\title{
Perubahan Penggunaan Lahan dan Keselarasan Rencana Pola Ruang Di Kota Kendari
}

\section{Changes of Land Use and Alignment of Spatial Planning in Kendari City}

\author{
Alwan ${ }^{1}$, Roland A. Barkey², Syafri ${ }^{3}$ \\ ${ }^{1}$ Magister Program Studi Perencanaan Wilayah dan Kota, Program Pascasarjana, Universitas Bosowa \\ ${ }^{2}$ Laboratorium Perencanaan dan Sistem Informasi Kehutanan, Fakultas Kehutanan, Universitas Hasanuddin \\ 3Program Studi Perencanaan Wilayah dan Kota, Program Pascasarjana, Universitas Bosowa \\ E-mail: aliwanci@gmail.com
}

Diterima: 01 Juli 2020/Disetujui 07 Desember 2020

\begin{abstract}
Abstrak. Inkonsistensi antara penggunaan lahan dengan arahan pola ruang merupakan tantangan dalam kebijakan pengendalian penggunaan lahan disetiap daerah, Perubahan penggunaan lahan di Kota Kendari dari tidak terbangun ke lahan terbangun cenderung cukup intensif yang salah satunya adalah akibat proses urbanisasi serta lemahnya kontrol pemanfaatan ruang Kota Kendari. Rumusan masalah yaitu bagaimana prediksi perubahan penggunaan lahan Kota Kendari tahun 2030 dengan rencana tata ruang wilayah Kota Kendari tahun 2010-2030. Tujuan penelitian adalah Manganalisis perubahan penggunaan lahan Kota Kendari tahun 2030 dengan rencana tata ruang wilayah Kota Kendari tahun 2010-2030. Jenis penelitian merupakan deskriptif analisis kualitatif melalui jawaban responden yang diambil diwilayah penelitian yaitu Wilayah Kota Kendari. Hasil pembahasan yaitu bahwa Prediksi penggunaan lahan ke tahun 2030 menunjukkan lahan terbangun sebesar 33,70\%, semak/belukar 14.49\%. Sementara itu, penggunaan lahan yang diprediksi mengalami penurunan terbesar pada tahun 2030 adalah kebun campuran sebesar 36,30\%, hutan $13.18 \%$, dan tambak $0.95 \%$. Kenaikan luas lahan terbangun akan selalu diikuti oleh penurunan kebun campuran, sedangkan kenaikan luas semak/belukar akan selalu diikuti oleh penurunan lahan hutan. Ketidakselarasan penggunaan lahan pada tahun 2019 adalah 783.89 ha $(2.89 \%)$ dari total luas wilayah dan pada akhir periode peruntukan RTRW tahun 2030 meningkat menjadi 1017.91 ha $(3.76 \%)$ dengan ketidakselarasan penggunaan lahan terbesar terjadi di kawasan hutan.
\end{abstract}

Kata Kunci: Perubahan Lahan, Pola Ruang, Keselaran, Perkotaan, Kendari

\begin{abstract}
The inconsistency between land use and spatial pattern direction is a challenge in the policy of controlling land use in each region. Changes in land use in Kendari City from non-built to built land tend to be quite intensive, one of which is as a result of the urbanization process and the weak control over spatial use of Kendari City. The research question is how to predict land use change in Kendari City in 2030 with the Kendari City spatial planning in 2010-2030. The research objective is to analyze land use changes in Kendari City in 2030 with the spatial planning for Kendari City in 2010-2030. The type of this research is descriptive qualitative analysis through respondents' answers taken in the research area, namely Kendari City. The results of the discussion are that the prediction of land use in 2030 shows that the built-up land is $33.70 \%$, with $14.49 \%$ shrubs. Meanwhile, land use which is predicted to experience the greatest decline in 2030 is $36.30 \%$ mixed gardens, $13.18 \%$ forest, and $0.95 \%$ ponds. The increase of built-up land is always followed by the decrease of mixed garden area while the increase of shrub area is always followed by the decrease of forest land. The nonalignment of land use in 2019 was $783.89 \mathrm{ha}(2.89 \%)$ of the total area and at the end of the period, RTRW allotment in 2030 increased to 1017.91 ha (3.76\%) with the largest inconsistency in land use occurring in forest areas.
\end{abstract}

Keywords: Land Change, Spatial Pattern, Aligment,Urban, Kendari

\section{Pendahuluan}

Lahan adalah lingkungan fisik yang terdiri atas iklim, relief, tanah, air, flora dan fauna, serta bentukan hasil budaya. Keadaan nyata lahan sangat penting bagi makhluk hidup karena lahan dapat diolah untuk mememenuhi kebutuhan manusia, pengolahan lahan tersebut dalam bentuk penggunaan lahan. Penggunaan lahan adalah setiap bentuk intervensi manusia terhadap lahan dalam rangka memenuhi kebutuhan hidupnya baik material maupun spiritual (Jamulya dan Sunarto,1995).

Seiring berjalannya waktu, dari tahun ke tahun mengalami pertumbuhan penduduk yang cukup pesat. Pertumbuhannnya yang terus bertambah akan diiringi dengan kebutuhan yang meningkat pula. Pemenuhan kebutuhan yang terus bertambah tidak diiringi dengan pertambahan lahan, sehingga banyak penggunaan lahan yang dibuat hanya berdasarkan kepentingan untuk memenuhi kebutuhannya sendiri yang terkadang melupakan kesesuaian lahannya. Salah satu dampaknya adalah perubahan fisik lahan (ruang) atau konversi lahan dari lahan pertanian menjadi lahan non pertanian Kebanyakan dari alih fungsi lahan ini bersifat irreversible. Pada kenyataannya telah diketahui bahwa luas lahan sebagai tempat aktivitas penduduk dalam rangka memenuhi kebutuhan hidup mereka dari waktu ke waktu akan terus berkurang. 
Perubahan pemanfaatan lahan yang terjadi di suatu daerah terkadang tidak sesuai dengan rencana tata ruang yang telah dibuat dan ditetapkan oleh pemerintah daerah setempat, seperti yang terdapat dalam Rencana Detail Tata Ruang (RDTR) 1:5000 Tahun 2015. Muatan rencana detail tata ruang mencakup rencana struktur ruang dan rencana pola ruang. Rencana struktur ruang meliputi rencana sistem pusat permukiman dan rencana sistem jaringan prasarana, sedangkan rencana pola ruang meliputi peruntukan kawasan lindung dan budidaya. Adanya peta rencana maka diharapkan dalam pembagunan dapat dievaluasi terarah dan sesuai dengan penataan ruangnya.Evaluasi penggunaan lahan pada daerah dapat diartikan sebagai usaha untuk pengendalian, penataan, dan perencanaan terhadap perkembangan daerah tersebut.

Kota Kendari merupakan Ibukota Provinsi Sulawesi Tenggara mengalami perubahan yang sangat dinamis, baik dalam pemanfaatan ruang maupun sosial ekonomi dan kelembagaannya. Kota Kendari sebagai kawasan pemerintahan dan perdagangan mempunyai skala prioritas utama pembangunan berupa fasilitas transportasi, komunikasi serta sarana dan prasarana, kedua posisi ini menjadikan Kota Kendari mempunyai daya tarik tersendiri. Daya tarik tersebut mendorong terjadinya arus urbanisasi. (RTRW Kota Kendari Tahun 2010-2030) menghasilkan peningkatan pendapatan bagi masyarakat yang ditunjukkan dengan peningkatan pendapatan per kapita.

Tata ruang yang telah ditetapkan menjadi peraturan daerah dalam kurun waktu tertentu seringkali mengalami ketidaksesuaian yang diakibatkan oleh pertumbuhan penduduk maupun perkembangan jaman, sehingga akan timbul yang namanya konversi lahan yang nantinya akan meningkatkan pertumbuhan kawasan seperti industri, kompleks perdagangan, perkantoran, dan fungsi strategis lainnya. Ketidakselarasan ini perlu dipantau dengan membandingkan pemanfaatan lahan yang ada saat ini atau eksisting dengan rencana pemanfaatan lahan yang merupakan salah satu materi dalam rencana tata ruang wilayah tersebut (Setiadi, 2006).

Perubahan penggunaan lahan di Kota Kendari dari tidak terbangun ke lahan terbangun cenderung cukup intensif yang salah satunya adalah akibat proses urbanisasi serta lemahnya kontrol pemanfaatan ruang Kota Kendari. Perubahan penggunaan lahan di Kota Kendari diduga merupakan dampak dari pertumbuhan perekonomian yang pesat. Pertumbuhan tersebut menyebabkan kebutuhan lahan untuk aktivitas ekonomi semakin meningkat, sementara ketersediaan lahan di Kota Kendari semakin terbatas. Akibatnya terjadi perkembangan lahan terbangun yang meluas ke wilayah-wilayah hinterland-nya. Faktor-faktor yang berkorelasi signifikan terhadap perubahan penggunaan lahan terdiri dari tiga faktor, yaitu faktor perubahan struktur ekonomi masyarakat, meningkatnya harga lahan, serta meningkatnya kondisi bangunan (Yusri et. al (2020),

Agar kegiatan masyarakat dapat berlangsung secara efisien dan menciptakan keterpaduan dalam pencapaian tujuan pembangunan, perlu dilakukan pengaturan alokasi lahan (Dardak, 2006). Penataan ruang bertujuan untuk mewujudkan ruang wilayah yang memenuhi kebutuhan pembangunan dengan senantiasa berwawasan lingkungan, efisien dalam pola alokasi investasi yang bersinergi dan dapat dijadikan acuan dalam penyusunan program pembangunan untuk tercapainya kesejahteraan masyarakat. Penataan ruang juga bertujuan untuk mengatur hubungan antara berbagai kegiatan dengan fungsi ruang guna tercapainya pemanfaatan ruang yang berkualitas, penataan ruang diharapkan dapat mengefisienkan pembangunan dan meminimalisasi konflik kepentingan dalam pemanfaatan ruang. Perencanaan tata ruang secara sederhana dapat diartikan sebagai kegiatan merencanakan pemanfaatan potensi dan ruang perkotaan serta pengembangan infrastruktur pendukung yang dibutuhkan untuk mengakomodasikan kegiatan sosial ekonomi yang diinginkan (Budiharjo, 1997)

Berdasarkan data BPS jumlah penduduk Kota Kendari tahun 2017 adalah 370.728 jiwa, dengan pertumbuhan penduduk 1,3\% per tahun (BPS Kota Kendari 2018). Distribusi penduduk di Kota Kendari belum merata. Kepadatan penduduk tertinggi di Kecamatan Kendari Barat yaitu $54.884 \mathrm{jiwa} / \mathrm{km} 2$ padahal luas wilayahnya hanya 7,77 persen dari luas keseluruhan Kota Kendari, sedangkan Kecamatan Kadia yang mempunyai wilayah paling luas tingkat kepadatan penduduknya yaitu 50.175 jiwa/km2. Hasil penelaahan awal dari overlay antara peta Rupa Bumi Indonesia (RBI) dengan peta pola ruang Rencana Tata Ruang Wilayah (RTRW) tahun 2010 menunjukan inkonsistensi antara penggunaan lahan eksisting dengan RTRW dilihat dari beberapa penggunaan lahan budidaya yang berada pada kawasan lindung. Penggunaan lahan tersebut adalah permukiman yang berada pada kawasan hutan kota sebesar 29,90 Ha, kawasan jalur hijau dengan luas 28,40 Ha dan kawasan Kebun Raya dan Taman Marga Satwa dengan luas 223,33 Ha.

Inkonsistensi antara penggunaan lahan dengan arahan pola ruang merupakan tantangan dalam kebijakan pengendalian penggunaan lahan disetiap daerah. Persamaan acuan peta, kelengkapan data, informasi, analisis dan rencana yang saling terkait, merupakan penentu dari kualitas perencanaan di suatu wilayah. Perubahan penggunaan lahan memiliki pola yang cenderung dinamis tergantung pada faktor pendorongnya.

Uraian tentang permasalahan penggunaan lahan dan adanya isu tentang dinamika yang sangat pesat di Kota Kendari mengindikasikan ketidaksesuaian penggunaan lahan eksisting dengan Rencana Tata Ruang Wilayah (RTRW) Kota Kendari tahun 2010-2030. Oleh karena itu, penginderaan jauh dengan pendekatan sistem informasi geografi dan pemodelan Cellular Automata-Markov (CAMarkov) dapat membantu mengidentifikasi, mengukur, menganalisa dan memprediksi perubahan-perubahan penggunaan lahan, sehingga dapat membantu mengendalikan penggunaan lahan dengan pola ruang agar inkonsistensi terhadap RTRW di suatu wilayah dapat dihindari.

Berdasarkan latar belakang dan masalah di atas, maka tujuan dalam penelitian ini adalah menganalisis perubahan penggunaan lahan Kota Kendari tahun 2030 dengan rencana tata ruang wilayah Kota Kendari tahun 2010-2030.

\section{Metode Penelitian}

a. Jenis Penelitian

Sesuai dengan jenis penelitian yang digunakan pada penelitian ini, yaitu jenis penelitian deskriptif kualitatif, maka jenis data yang digunakan terdiri dari data kualitatif. 
b. Lokasi Penelitian

Data kualitatif adalah data yang berupa keterangan atau kata-kata biasa, sedangkan data kuantitatif adalah data yang berupa angka. Di samping itu, berdasarkan cara memperolehnya, penelitian ini menggunakan data primer dan data sekunder. Data primer adalah data yang diperoleh langsung dari responden, dan data sekunder diperoleh dari kepustakaan (hasil-hasil penelitian dan kajian sebelumnya) dan dokumen kebijakan (program) yang berhubungan dengan masalah penelitian, yang juga berguna untuk melengkapi data yang diperoleh dari hasil survey lapangan.

\section{c. Lokasi Penelitian}

Lokasi penelitian adalah di Wilayah Kota Kendari terletak di jazirah Tenggara Pulau Sulawesi. Wilayah daratannya sebagian besar terdapat di daratan Pulau Sulawesi mengelilingi Teluk Kendari dan terdapat satu pulau yaitu Pulau Bungkutoko. Luas wilayah daratan Kota Kendari 295,89 Km2 atau 0,70 persen dari luas daratan Provinsi Sulawesi Tenggara. Waktu penelitian dilaksanakan selama 3 (tiga) bulan yakni pada bulan Oktober - Desember tahun 2019.

\section{d. Penentuan Informan}

Dalam penelitian ini yang dijadikan informan sasaran adalah kepala dinas pekerjaan umum dan tata ruang kota kendari, kepala seksi perencanaan tata ruang kota kendari, pengembang dan tokoh masyarakat, maka teknik pengambilan sampel yang digunakan adalah purposive sampling yaitu mewawancarai responden yang berjumlahnya sedikit.

\section{Hasil dan Pembahasan}

Hasil dan pembahasan dalam penelitian ini menguraikan tentang perubahan penggunaan lahan dan keselarasan rencana pola ruang di Kota Kendari. Pembahasan tersebut dijabarkan sebagai berikut:

\subsection{Analisis perubahan penggunaan lahan Kota Kendari} tahun 2030 dengan rencana tata ruang wilayah Kota Kendari tahun 2010-2030

Berdasarkan nilai probabilitas, kemungkinan penambahan luas penggunaan lahan permukiman sebesar $36.30 \%$. Sedangkan penggunaan lahan lainnya kemungkinan mengalami penurunan luasan. Prediksi perubahan penggunaan lahan tahun 2030 belum mempertimbangkan faktor intervensi kebijakan di dalamnya (business as usual), artinya belum ada campur tangan pemerintah dalam upaya mengendalikan penggunaan lahan. Berdasarkan hasil prediksi penggunaan lahan untuk tahun 2030, diperoleh luasan penggunaan lahan terbesar masih didominasi oleh kebun campuran sebesar $33.70 \%$ (Gambar 1), meskipun setiap tahunnya mengalami penurunan. Penggunaan lahan lainnya secara berturut-turut adalah hutan $13.18 \% \%$, tambak $0.95 \%$, sawah $0.70 \%$, kebun mangrove $0.42 \%$, kebun campuran $36.30 \%$. Hasil prediksi penggunaan lahan pada tahun tahun 2019-2030 disajikan pada Tabel 1 .
Tabel 1. Prediksi Penggunaan Lahan Wilayah Kota Kendari Tahun 2030

\begin{tabular}{|c|c|c|c|c|c|c|}
\hline \multirow{2}{*}{$\begin{array}{l}\text { Penggun } \\
\text { Lahan }\end{array}$} & \multicolumn{2}{|c|}{ Tahun 2019} & \multicolumn{2}{|c|}{ Tahun 2030} & \multicolumn{2}{|c|}{$\begin{array}{c}\text { Perubahan dari } \\
2019 \text { - 2030 }\end{array}$} \\
\hline & $\begin{array}{l}\text { Luas } \\
(\mathrm{Ha})\end{array}$ & $\%$ & $\begin{array}{c}\text { Luas } \\
(\mathrm{Ha})\end{array}$ & $\%$ & $\begin{array}{c}\text { Luas } \\
(\mathrm{Ha})\end{array}$ & $\%$ \\
\hline Hutan & 4942.01 & 18.24 & 3570.42 & 13.18 & -1371.59 & -5.06 \\
\hline $\begin{array}{l}\text { Kebun } \\
\text { Campuran }\end{array}$ & 10425.5 & 38.48 & 9832.99 & 36.30 & -592.58 & -2.19 \\
\hline Mangrove & 188.01 & 0.69 & 112.63 & 0.42 & -75.38 & -0.28 \\
\hline Permukiman & 7163.31 & 26.44 & 9130.49 & 33.70 & +1967.1 & +7.26 \\
\hline Sawah & 257.95 & 0.95 & 190.21 & 0.70 & -67.74 & -0.25 \\
\hline $\begin{array}{l}\text { Semak } \\
\text { Belukar }\end{array}$ & 3745.61 & 13.83 & 3926.64 & 14.49 & +181.03 & +0.67 \\
\hline Tambak & 279.14 & 1.03 & 257.92 & 0.95 & -21.22 & -0.08 \\
\hline Tubuh Air & 89.93 & 0.33 & 69.73 & 0.26 & -20.20 & -0.07 \\
\hline Jumlah & 27091.5 & 100 & 27091.5 & 100 & & \\
\hline
\end{tabular}

Sumber: Hasil Analisis, 2020

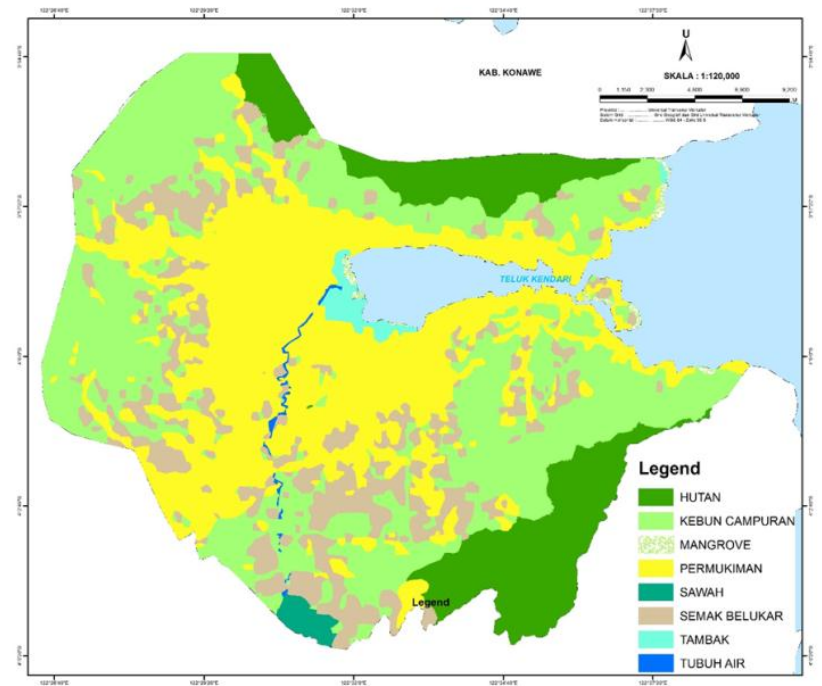

Gambar 1 Prediksi Penggunaan Lahan Tahun 2030

Jenis penggunaan lahan yang diprediksi mengalami kenaikan luasan yang cukup signifikan dibanding luasan lahan sebelumnya dari tahun 2019-2030 di wilayah Kota Kendari adalah lahan terbangun sebesar 33,70\%, semak/belukar $14.49 \%$. Sementara itu, penggunaan lahan yang diprediksi mengalami penurunan terbesar pada tahun 2030 adalah kebun campuran sebesar 36,30\%, hutan $13.18 \%$, dan tambak $0.95 \%$. Kenaikan luas lahan terbangun akan selalu diikuti oleh penurunan kebun campuran, sedangkan kenaikan luas semak/belukar akan selalu diikuti oleh penurunan lahan hutan.

\subsection{Ketidakselarasan Pemanfaatan Lahan RTRW Kota Kendari}

Berdasarkan hasil analisis overlaping peta penggunaan lahan tahun 2019 dengan peta RTRW diperoleh hasil bahwa 783,89 ha (2.89\%) penggunaan lahan di Kota Kendari tidak selaras (inkonsisten) terhadap arahan RTRW. Hasil analisis keselarasan RTRW 2010-2030 dengan panggunaan lahan aktual tahun 2019 disajikan pada Tabel 2 dan Tabel 3. 
Tabel 3 Potensi Masalah RTRW dengan Penggunaan Lahan Aktual Tahun 2019

\begin{tabular}{|c|c|c|}
\hline $\begin{array}{c}\text { Potensi Masalah Tata Ruang Tahun } \\
2030 \\
\end{array}$ & Luas (Ha) & $\%$ \\
\hline Hutan----> Kebun Campuran & 39.71 & $0.15 \%$ \\
\hline Hutan----> Permukiman & 7.83 & $0.03 \%$ \\
\hline Hutan----> Semak Belukar & 0.94 & $0.00 \%$ \\
\hline $\begin{array}{l}\text { Kawasan Resapan Air---> } \\
\text { Permukiman }\end{array}$ & 31.95 & $0.12 \%$ \\
\hline Kawasan RTH Kota---> Permukiman & 124.44 & $0.46 \%$ \\
\hline Kawasan RTH Kota---> Tubuh air & 6.39 & $0.02 \%$ \\
\hline Kawasan RTH Kota---> Tambak & 120.56 & $0.45 \%$ \\
\hline $\begin{array}{l}\text { Kawasan Sempadan Pantai dan } \\
\text { Sungai---> Permukiman }\end{array}$ & 121.93 & $0.45 \%$ \\
\hline $\begin{array}{l}\text { Kawasan Sempadan Pantai dan } \\
\text { Sungai---> Tubuh Air }\end{array}$ & 79.68 & $0.29 \%$ \\
\hline $\begin{array}{l}\text { Kawasan Hutan Rakyat---> } \\
\text { Permukiman }\end{array}$ & 15.62 & $0.06 \%$ \\
\hline $\begin{array}{l}\text { Kawasan Kebun Raya---> } \\
\text { Permukiman }\end{array}$ & 10.02 & $0.04 \%$ \\
\hline Kawasan Perumahan ---> Mangrove & 82.97 & $0.31 \%$ \\
\hline Kawasan Perumahan ---> Tambak & 121.75 & $0.45 \%$ \\
\hline Kawasan Pertanian---> Permukiman & 20.10 & $0.07 \%$ \\
\hline Jumlah & 783.89 & $2.89 \%$ \\
\hline
\end{tabular}

Dari hasil analisis keselarasan RTRW dengan penggunaan lahan aktual tahun 2019 diketahui bahwa pada tahun 2019 terdapat ketidak selarasan arahan penataan ruang dengan kondisi eksisting sebesar 783,89 ha atau $2.89 \%$ dari total luas Kota Kendari. Ketidak selarasan tata ruang tersebut meliputi penggunaan lahan non hutan seperti kebun campuran, permukiman, semak belukar yang terdapat di lokasi kawasan hutan, Kota kendari tidak mampu mewujudkan areal hutan seluas alokasi ruang yang sudah direncanakan dalam RTRW.

Masalah penataan ruang berikutnya yang diakibatkan oleh ketidakselarasan RTRW dengan penggunaan lahan tahun 2019 adalah dimanfaatkannya kawasan RTH kota untuk pengembangan permukiman sebesar 124.44 ha atau $0.46 \%$ dari total luas Kota Kendari. Hal ini menunjukkan bahwa perlindungan kawasan RTR kota tidak cukup berhasil sehingga kawasan yang dialokasikan sebagai RTH Kota digunakan sebagai kawasan permukiman dan akan mengurangi luas kawsan RTH yang sudah di rencanakan.

Berdasarkan hasil analisis overlaping peta penggunaan lahan tahun 2030 dengan peta RTRW diperoleh hasil bahwa 1017.91 ha $(3,76 \%)$ penggunaan lahan di Kota Kendari tidak selaras (inkonsisten) terhadap arahan RTRW. Hasil analisis keselarasan RTRW 20102030 dengan panggunaan lahan hasil prediksi marcov pada tahun 2030 disajikan pada Tabel 4 dan Tabel 5.

Tabel 5 Potensi Masalah Penataan Ruang di Kota Kendari Tahun 2030

\begin{tabular}{|c|c|c|}
\hline $\begin{array}{l}\text { Potensi Masalah Tata Ruang Tahun } \\
\qquad 2030\end{array}$ & $\begin{array}{r}\text { Luas } \\
\text { (Ha) }\end{array}$ & $\begin{array}{c}\text { Persen } \\
\%\end{array}$ \\
\hline Hutan----> Kebun Campuran & 139.60 & $0.52 \%$ \\
\hline Hutan----> Permukiman & 23.18 & $0.09 \%$ \\
\hline Hutan----> Semak Belukar & 14.87 & $0.05 \%$ \\
\hline Kawasan Resapan Air---> Permukiman & 142.85 & $0.53 \%$ \\
\hline Kawasan RTH Kota---> Permukiman & 198.95 & $0.73 \%$ \\
\hline Kawasan RTH Kota---> Tambak & 110.35 & $0.41 \%$ \\
\hline $\begin{array}{l}\text { Kawasan Sempadan Pantai dan Sungai---> } \\
\text { Permukiman }\end{array}$ & 170.21 & $0.63 \%$ \\
\hline
\end{tabular}

\begin{tabular}{lcc}
\hline \multicolumn{1}{c}{$\begin{array}{c}\text { Potensi Masalah Tata Ruang Tahun } \\
\text { 2030 }\end{array}$} & $\begin{array}{c}\text { Luas } \\
\text { (Ha) }\end{array}$ & $\begin{array}{c}\text { Persen } \\
\text { \% }\end{array}$ \\
\hline Kawasan Hutan Rakyat---> Permukiman & 35.74 & $0.13 \%$ \\
Kawasan Kebun Raya---> Permukiman & 17.79 & $0.07 \%$ \\
Kawasan Perumahan ---> Mangrove & 33.37 & $0.12 \%$ \\
Kawasan Perumahan ---> Tambak & 117.62 & $0.43 \%$ \\
Kawasan Pertanian---> Permukiman & 13.36 & $0.05 \%$ \\
\hline \multicolumn{1}{c}{ Jumah } & 1017.91 & $3.76 \%$ \\
\hline
\end{tabular}

Sumber: Hasil Analisis, 2020

Tabel 4 dan Tabel 5 menejelaskan dari hasil prediksi Markov terdapat 1017.91 ha atau $3.76 \%$ ketidakselarasan RTRW dengan prediksi penggunaan lahan tahun 2030 yang berpotensi menjadi permasalahan tata ruang di Kota Kendari pada tahun 2030. Adapun potensi masalah tersebut meliputi potensi konflik penguasaan lahan di kawasan hutan karena teridentifikasinya penggunaan lahan non hutan pada kawasan hutan. Penggunaan lahan non hutan tersebut berupa kebun campuran $(0.52 \%)$, lahan terbangun $(0.09 \%)$ dan semak belukar $(0.05 \%)$,. Hal tersebut melanggar peraturan tata ruang mengenai kawasan hutan, dimana kawasan hutan merupakan suatu wilayah tertentu yang ditunjuk dan/atau ditetapkan oleh pemerintah untuk dipertahankan keberadaannya sebagai hutan tetap yang terdiri dari hutan konservasi, hutan lindung, hutan produksi terbatas, dan hutan produksi tetap. Adapun sebaran spasial dari potensi permasalahan di Kota Kendari tahun 2030 dapat dilihat pada Gambar 2.

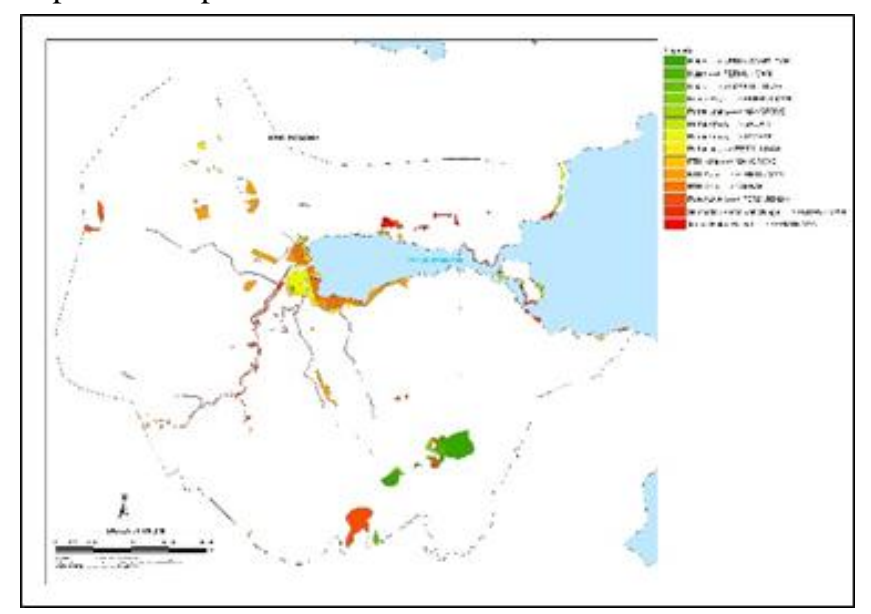

Gambar 2 Sebaran Spasial dan Potensi Permasalahan di Kota Kendari

Oleh sebab itu, pada tahun 2030 terdapat potensi kehilangan fungsi hutan yang terdiri dari berkurangnya kawasan hutan lindung sebesar 177.65 ha atau 0,66 \% serta berkurangnya kawasan hutan rakyat sebesar 35.74 ha atau $0,13 \%$ dan kawasan resapan air sebesar 142.85 ha atau $0,53 \%$. Kondisi ini mengancam fungsi hutan sebagai kawasan lindung dan sebagai daerah resapan air yang menaungi dan melindungi wilayah-wilayah di yang relative rendah. Akibatnya dapat meningkatkan peluang terjadinya bencana banjir saat musim hujan.

Selain kawasan hutan, potensi masalah tata ruang di Kota Kendari pada tahun 2030 adalah ketidakselarasan pada kawasan RTH Kota yang dalam penggunaan lahannya diduga akan terkonversi menjadi lahan terbangun sebesar 198.95 ha atau $0,73 \%$ dari total luas Kota Kendari. Hal ini menunjukkan bahwa Kota kendari berpotensi kehilangan ruang terbuka hijua sebesar $23 \%$ dari alokasi yang ditetapkan dalam RTRW. 
Tabel 2 Matriks Keselarasan RTRW Kota Kendari Tahun 2010-2030 dengan Penggunaan Lahan Aktual Tahun 2019

\begin{tabular}{|c|c|c|c|c|c|c|c|c|c|}
\hline \multirow[b]{2}{*}{ RTRW 2010-2030 } & \multicolumn{9}{|c|}{ Penggunaan Lahan Eksisting Tahun 2019} \\
\hline & Hutan & $\begin{array}{c}\text { Kebun } \\
\text { Campuran }\end{array}$ & Mang-rove & Permukiman & Sawah & Semak Belukar & Tambak & $\begin{array}{c}\text { Tubuh } \\
\text { Air }\end{array}$ & Jumlah \\
\hline Hutan & 1817.61 & 39.71 & & 7.83 & & 0.94 & & & 1866.09 \\
\hline Industri & 319.81 & 1442.70 & 2.56 & 167.97 & & 123.46 & 4.74 & & 2061.24 \\
\hline Kebun Raya & 32.70 & 38.01 & & 10.02 & & 24.01 & & & 104.73 \\
\hline Pariwisata & 64.57 & 1686.93 & 3.03 & 116.59 & 0.14 & 213.54 & 6.86 & 0.14 & 2091.81 \\
\hline Permukiman & 167.08 & 4973.21 & 82.97 & 6536.29 & 4.11 & 2807.46 & 121.75 & 2.63 & 14695.49 \\
\hline Pertanian & & 773.76 & & 20.10 & 236.91 & 165.16 & & 1.04 & 1196.98 \\
\hline Resapan Air & 312.48 & 643.70 & & 31.95 & 12.73 & 129.96 & & & 1130.82 \\
\hline RTH Kota & 211.40 & 227.82 & 44.76 & 124.44 & & 133.43 & 120.56 & 6.39 & 868.81 \\
\hline Sempadan Pantai dan Sungai & 8.66 & 62.77 & 51.54 & 121.93 & 2.98 & 62.61 & 23.56 & 79.68 & 413.73 \\
\hline Taman Hutan Rakyat & 1997.97 & 531.06 & & 15.62 & & 82.97 & & & 2627.62 \\
\hline
\end{tabular}

Tabel 4 Matriks Keselarasan RTRW Kota Kendari Tahun 2010-2030 dengan Penggunaan Lahan Aktual Tahun 2019

\begin{tabular}{|c|c|c|c|c|c|c|c|c|c|}
\hline \multirow[b]{2}{*}{ RTRW 2010-2030 } & \multicolumn{9}{|c|}{ Prediksi Penggunaan Lahan Tahun 2030} \\
\hline & Hutan & Kebun Campuran & nMangrove & Permkiman & Sawah & Semak Belukar & Tambak & $\begin{array}{l}\text { Tubuh } \\
\text { Air }\end{array}$ & Jumlah \\
\hline Kawasan Hutan Lindung & 1688.55 & 139.60 & & 23.18 & & 14.87 & & & 1866.21 \\
\hline Kawasan Industri & 111.21 & 1580.74 & 0.00 & 219.13 & & 150.41 & & & 2061.49 \\
\hline Kawasan Kebun Raya & 2.14 & 51.94 & & 17.79 & & 32.85 & & & 104.73 \\
\hline Kawasan Pariwisata & 12.06 & 1690.06 & 3.88 & 169.68 & & 218.84 & 1.71 & 0.04 & 2096.26 \\
\hline Kawasan Perumahan \& Ll & 11.33 & 3671.40 & 33.37 & 8138.14 & 1.44 & 2725.07 & 117.62 & 1.88 & 14700.24 \\
\hline Kawasan Pertanian & & 760.98 & & 13.36 & 174.19 & 247.56 & & 0.92 & 1197.02 \\
\hline Kawasan Resapan Air & 119.85 & 650.21 & & 142.85 & 10.46 & 207.44 & & & 1130.82 \\
\hline Kawasan RTH Kota & 145.28 & 231.39 & 27.16 & 198.95 & & 151.36 & 110.35 & 4.65 & 869.13 \\
\hline Kawasan Sempadan Pantai dan Sungai & 8.14 & 50.31 & 48.22 & 170.21 & 3.45 & 46.99 & 28.24 & 62.24 & 417.81 \\
\hline Kawasan Hutan Rakyat & 1462.99 & 999.20 & & 35.74 & & 129.69 & & & 2627.62 \\
\hline
\end{tabular}

\section{Kesimpulan dan Saran}

Hasil penelitian dapat disimpulkan bahwa perubahan penggunaan lahan di Kota Kendari pada periode 2008-2019 didominasi oleh bertambahnya lahan terbangun,tambak dan sawah. Pertambahan ini diikuti dengan berkurangnya luasan hutan, kebun campuran, mangrove dan semak belukar. Prediksi penggunaan lahan ke tahun 2030 menunjukkan lahan terbangun sebesar 33,70\%, semak/belukar $14.49 \%$. Sementara itu, penggunaan lahan yang diprediksi mengalami penurunan terbesar pada tahun 2030 adalah kebun campuran sebesar 36,30\%, hutan $13.18 \%$, dan tambak $0.95 \%$.Kenaikan luas lahan terbangun akan selalu diikuti oleh penurunan kebun campuran, sedangkan kenaikan luas semak/belukar akan selalu diikuti oleh penurunan lahan hutan. Ketidakselarasan penggunaan lahan pada tahun 2019 adalah 783.89 ha (2.89\%) dari total luas wilayah dan pada akhir periode peruntukan RTRW tahun 2030 meningkat menjadi 1017.91 ha (3.76\%) dengan ketidakselarasan penggunaan lahan terbesar terjadi di kawasan hutan.

\section{Daftar Pustaka}

BPS,2018 .Kota Kendari Dalam Angka tahun 2018, Kendari:BPS Kota Kendari.

Budiharjo, Eko (Ed.). 1997. Arsitektur Pembangunan dan Konservasi, Jakarta: Penerbit Djambatan.

Dardak, Hermanto. 2005. Pemanfaatan Lahan Berbasis Rencana Tata Ruang sebagai Upaya Perwujudan Ruang Hidup yang Nyaman, Produktif, dan Berkelanjutan.
Jamulya, dan Sunarto 1995. Evaluasi Sumberdaya Lahan: Kemampuan Lahan. Yogyakarta : Fakultas Geografi UGM.

Setiadi, Arief. F. (2006). Pemanfaatan Citra Satelit Ikonos dan Sistem Informasi Geografi untuk Pemantauan Pemetaaan Rencana Detail Tata Ruang (RDTR) Kota Surakarta Bagian Selatan (Kasus Satuan Wilayah Pengembangan I dan II). Tugas akhir. Yogyakarta: Fakultas Geografi UGM.

Peraturan Daerah Nomor 1 Tahun 2012 tentang Rencana Tata Ruang Kota Kendari

Yusri, Y., Syafri, S., \& Saleh, H. (2020). Perubahan Fungsi Lahan Perkotaan Kabupaten Bone. Studi Kasus: Koridor Jalan Sungai Pareman Kecamatan Tanete Riatang Timur. Urban and Regional Studies Journal, 2(1), 31-36. 